\title{
Solar Energy
}

\section{Increasing efficiency of photovoltaic systems under non- homogeneous solar irradiation using improved dynamic programming methods}

\author{
Thanh Ngo Ngoc ${ }^{\mathrm{ab}}$, Quang Nguyen Phung ${ }^{\mathrm{c}}$, Linh Nguyen Tung ${ }^{\mathrm{a}}$, \\ Eleonora Riva Sanseverino ${ }^{\mathrm{d} *}$, Pietro Romano ${ }^{\mathrm{d}}$, Fabio Viola ${ }^{\mathrm{d}}$ \\ ${ }^{a}$ Electric Power University, HaNoi, VietNam \\ ${ }^{b}$ Vietnam Academy of Science and Technology \\ ${ }^{c}$ Hanoi University of Science and Technology, HaNoi, VietNam \\ ${ }^{d}$ DEIM, University of Palermo, Palermo, Italy
}

\begin{abstract}
The paper presents a complete technique, based on the combination of algorithms, devoted to minimize losses and increase efficiency of Total Cross Tied (TCT) connected photovoltaic (PV) systems under non-homogeneous solar irradiation, based on irradiance equalization criterion. Irradiance equalization is achieved by changing the connections of the solar panels adaptively by a dynamic switching matrix so that total solar radiation on parallel circuits is the most equalized.

In this paper, the authors introduce two algorithms. The first one is SmartChoice (SC) algorithm, which is combined with Dynamic Programming (DP) in order to create a hybrid method and obtain better results as compared to established methods for irradiance equalization. The second one is the control algorithm improvement method from Munkres' Assignment Algorithm (MAA) that helps to increase processing speed and lengthen the lifetime of the solar power system by $56 \%$ compared with the older MAA.

By emulating and experiencing the operation of the PV system under non-homogeneous irradiation condition, obtained results show efficiency and benefits of the proposed method applied to the solar power system operation while lengthening the lifetime of the switching matrix.
\end{abstract}

(C)2015 Elsevier Ltd. All rights reserved.

Keywords:Mismatch, Photovoltaic modules, Optimization, Reconfiguration.

2210-9838 @ 2014 The Authors. Published by Elsevier B.V.

Selection and peer-review under responsibility of ABCM (Brazilian Society of Mechanical Sciences and Engineering). 


\section{Nomenclature}

\begin{tabular}{|ll|}
\hline avg & average sum of irradiance on the row after reconfiguration \\
DES & Dynamic Electrical Scheme \\
$\mathrm{EI}$ & Equalization Index \\
$\mathrm{N}$ & number of panels \\
$\mathrm{i}$ & row index \\
$\mathrm{I}-\mathrm{V}$ & current-voltage \\
$\mathrm{j}$ & column index \\
$\mathrm{m}$ & number of rows \\
$\mathrm{MPP}$ & maximum power point \\
$\mathrm{MPPT}$ & Maximum power point tracker \\
$\mathrm{n}_{\mathrm{i}}$ & number of modules that are parallel connected of the row i \\
$\mathrm{G}$ & total irradiance \\
$\mathrm{P}-\mathrm{V}$ & power-voltage \\
$\mathrm{G}_{\mathrm{i}}$ & total irradiance of the row i \\
$\mathrm{G}_{\mathrm{ij}}$ & irradiance value of module located on row i and column $\mathrm{j}$ \\
$\mathrm{PS}$ & partial shading \\
$\mathrm{PV}$ & photovoltaic \\
$\mathrm{TCT}$ & Total-cross-tied \\
$\mathrm{MAA}$ & Munkres' Assignment Algorithm \\
$\mathrm{DP}$ & Dynamic programming \\
$\mathrm{SC}$ & Smartchoice \\
\hline
\end{tabular}

\section{Introduction}

Power crisis is becoming prominent issue, not only endangering the global economic growth but also international security and peace. Fossil power source, an extremely precious present that nature grants for society, is gradually exhausting. Thus, renewable energy has become a hot topic on the international agenda. The European Union has committed to reduce the emissions of greenhouse gas by at least $20 \%$ below the level in 1990 and by almost $100 \%$ by 2050. Consumption coverage from renewables must also reach $20 \%$ by 2020 and almost $100 \%$ by 2050 .

In this context, solar power plays an important role due to the fact that it is a green source. The solar power generates electricity from solar irradiation without emitting direct carbon dioxide and greenhouse gas. Besides, electrical power supply from power plants to remote consumption locations can be very costly especially in developing countries. Small solar power plants may solve these issues by bringing power sources to be near the power charging station to minimize or replace completely the usage of generators that use diesel fuel. This will bring long-term public economic benefits without any environmental and economic cost. On the other hand, building a solar power plant needs a more expensive investment as compared to other power plants (i.e. hydropower plant, thermal power plant, etc). Although Levelized Cost of Energy is progressively reducing (Adnam, 2015) driven by the reduction of the cost of modules. Researchers on solar power technologies in the near future is now promoted strongly to reduce power production costs to make it competitive with other power resources (International Energy Agency, 2013 Lynn, 2011). In recent scientific papers, a big amount of publications is devoted to algorithms development, architectures and control techniques in applications of the PV system for Maximum Power Point Tracking (MPPT) (Veerachary et al., 2002; Alireza et al., 2013; Balato et al., 2016; Yi-Hua et al., 2014; Jian et al., 2015; Po-Cheng et al., 2015; Zhang et al., 2015).

However, during operation, there are many cases in which PV panels in the solar power plants can receive nonhomogeneous radiation levels. The causes may be a lot such as shadow due to clouds, trees, houses and antenna pole. This results in inefficiency in operation of most of techniques on MPPT (Femia et al., 2012) leading the falling of the 
output power. Moreover, it can cause hotspot phenomenon at shaded solar cell panels, thus damaging directly solar cells (Woytea et al., 2003; Shams et al., 2012).

Effects due to partial shading (PS) of the PV system are given in Woytea et al. (2003) and in ; Shams et al., (2012). When in shading, the system is not only subjected to possible damage but also to misleading phenomena for the MPPT algorithm. The latter indeed will find many sub optimal working points.

With respect to this phenomenon, power loss of the solar power system is divided into two parts: recoverable loss and non-recoverable loss. At present, operative techniques for recovering losses could be grouped into the following main three categories:

- Distributed MPPT;

- Multilevel inverters;

- Photovoltaic array reconfiguration.

An exhaustive description of distributed MPPT and the employment of multilevel inverters is beyond the scope of this article, based on the array reconfiguration. One main research scope for power losses recovery is to develop the reconfiguration strategy of the solar power system (Velasco et al., 2005; Belhachata et al., 2015; Nguyen and Leman, 2008; Alahmada et al., 2012; Guillermo et al., 2009; Hideaki Obane et al., 2012; Storey et al., 2012; La Manna et al., 2014). The reconfiguration is an efficient rearrangement of connections of solar panels in order to increase the output power and protect the equipment when the system is working under non-homogeneous solar irradiation conditions. For instance, when one or more solar panels in the connection circuit is shaded, the generated power will be decreased causing an increase of the power losses in the system ( Delinea et al., 2013).

In Riva Sanseverino et al., (2015), authors offered Dynamic programming (DP) method to find out the optimal connection configuration for PV panels and used Munkres Assignment Algorithm (MAA) to find out the best switching configuration in order to increase the lifetime of the switching matrix. Through analysis and simulation, these proposed methods obtained better results than those presented in Velasco et al., (2009), Storey et al., (2012) and Romano et al., (2013).

In this paper, authors initially propose a new heuristic algorithm, Smart Choice, which, combined to DP, improves the selection of the arrangement of the panels. The paper then introduces an improvement to the MAA that produces a computation time reduction. Finally, extensive simulations prove the efficiency of the proposed algorithms and finally a prototype allows to assess the effectiveness and accuracy of the proposed overall technique.

\section{Reconfiguration strategy for TCT topology}

Reconfiguration strategy for TCT topology is shown in details in Riva Sanseverino et al., (2015). The TCT topology (Fig. 1a) combined with a Dynamic Electrical Scheme (DES) switching matrix (Romano et al., 2013) (Fig.1b) allows, through switching operations, to move from the initial TCT interconnection to a new TCT interconnection with any configuration (Fig. 1c).

Ampere meter and voltmeter are installed at each PV panel to measure current and voltage. Based on the current and the voltage measured from each PV panel, the formula to calculate the irradiation level (Velasco et al., 2009) can be used to estimate the irradiation level obtained from the PV panels.

In the general connection diagram shown in Fig. 1c, if $\mathrm{G}_{\mathrm{ij}}$ is the irradiance value of the PV panel located on row $\mathrm{i}$ and column $j$ in TCT circuit, then the total irradiation of row $i$ known as $G_{i}$ is defined as:

$$
G_{i}=\sum_{j=1}^{n_{i}} G_{i j}
$$

The total irradiation $\mathrm{G}$ is equal to:

$$
G=\sum_{i=1}^{m} G_{i}
$$


The number of modules $\mathrm{N}$ is equal to:

$$
N=\sum_{i=1}^{m} n_{i}
$$

where $n_{i}$ is the number of PV panels that were connected in parallel and are located on row $i$. The number of rows in which the TCT circuit can be arranged $m$ must be compatible with the inverter input voltage operating range. In order to maximize the output power of the TCT connection, the sum of irradiance on each row after reconfiguration should be equal or close to the average level

$$
\operatorname{avg}=\frac{G}{m}
$$

After reconfiguration, Equalization Index (EI) [21] for the new configuration is equal to:

$$
E I=\max _{i}\left(G_{i}\right)-\min _{i}\left(G_{i}\right)
$$

The configuration with the minimum EI index that generates the maximum output power is an optimal configuration and shall be selected.
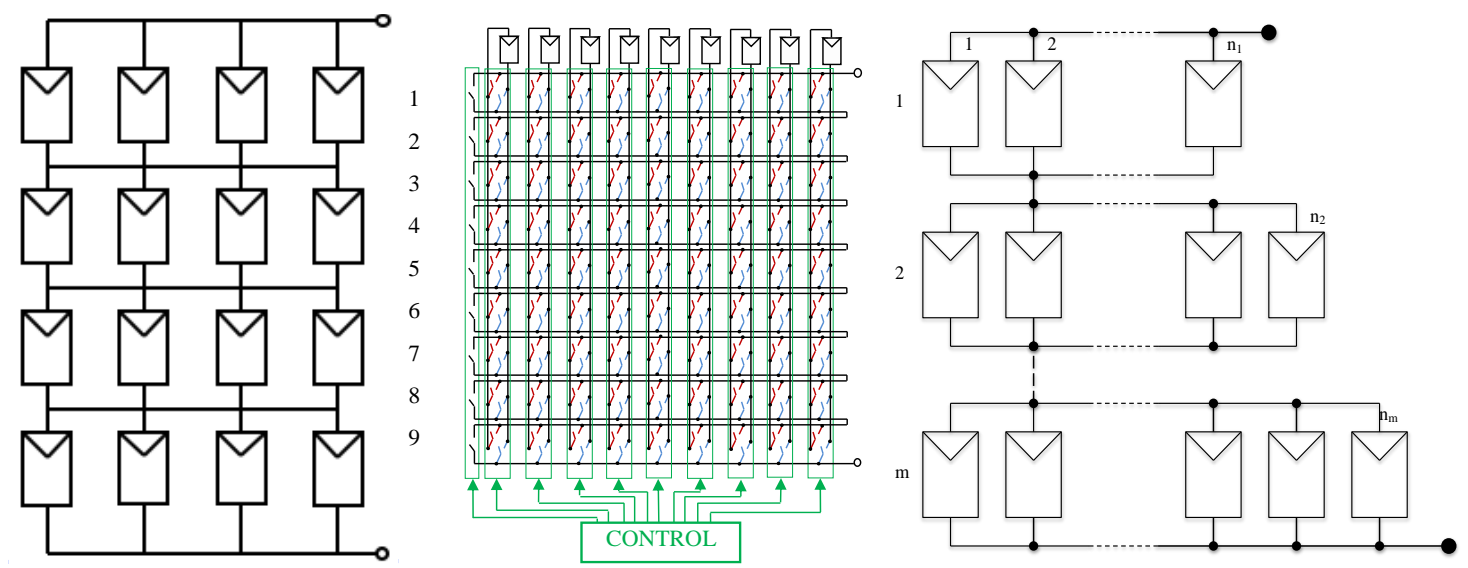

Fig.1. a) TCT topology; b) Dynamic Electrical Scheme (DES) switching matrix [24], c) Generator topology

A next important issue is to reduce the number of switching operations from the initial configuration to the optimal configuration. For the configurations with similar EI index, the configuration with the most reasonable times of transversion shall be selected. This shall lengthen the lifetime of the switching matrix so that aging of all the switches is homogeneous. Increasing the operation efficiency of the solar power systems based on irradiance equalization can be summarized according to the flow chart in Fig. 2 (La Manna et al., 2014).

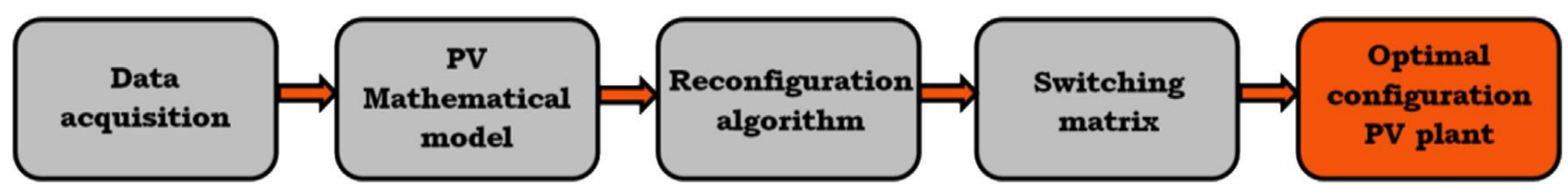

Fig.2. Dynamic reconfiguration system for PV plant: flow chart for optimal design [21]

Efficiency of this method is shown in Fig.3. After reconfiguration, efficiency of the system increases by $60 \%$ and transversion from the initial configuration to the optimal configuration needs only 3 times of switching operations (Riva Sanseverino et al., 2015). 


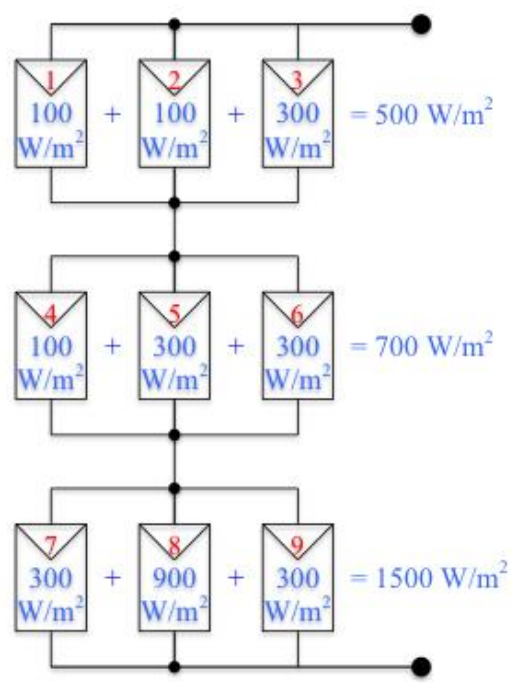

(a).

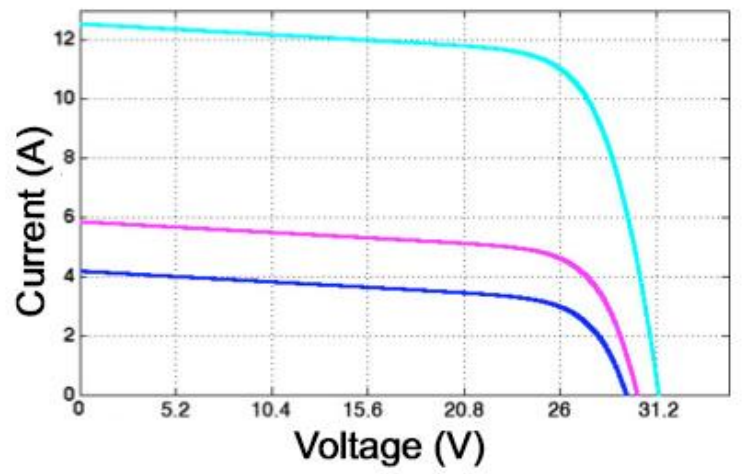

(b)

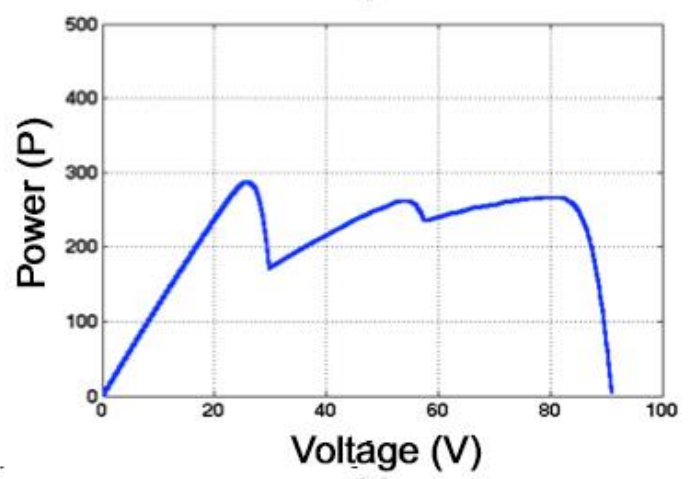

(c)

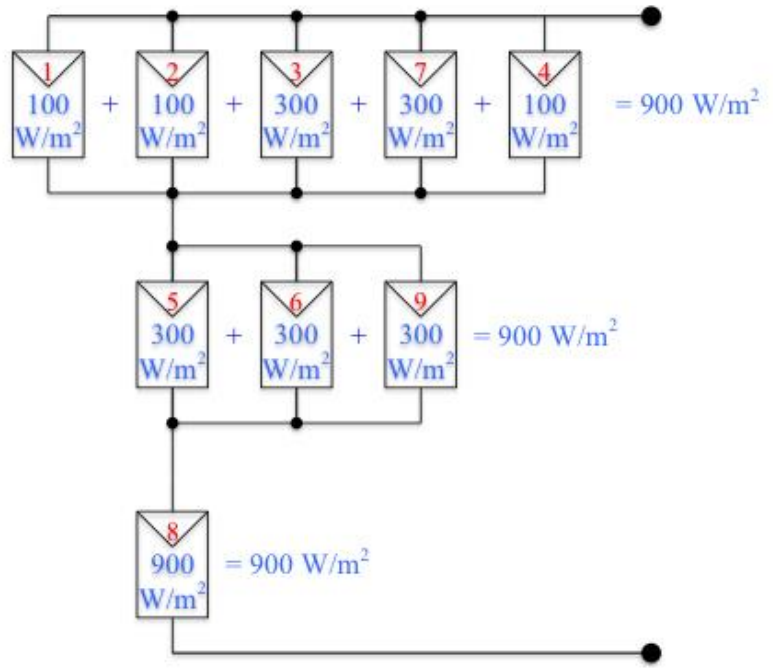

(d)

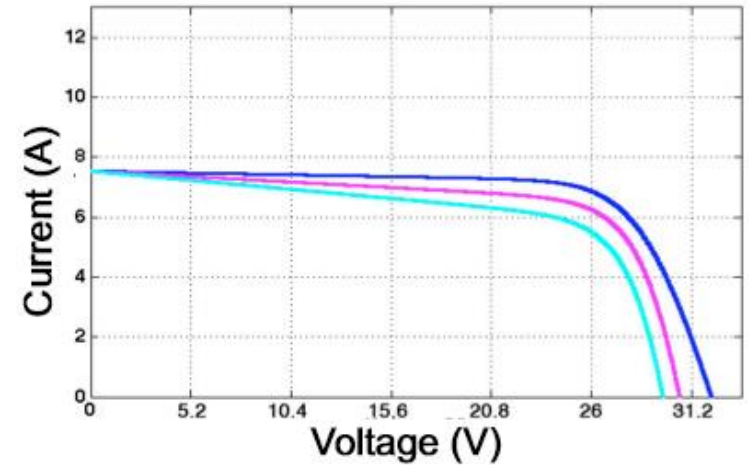

(e)

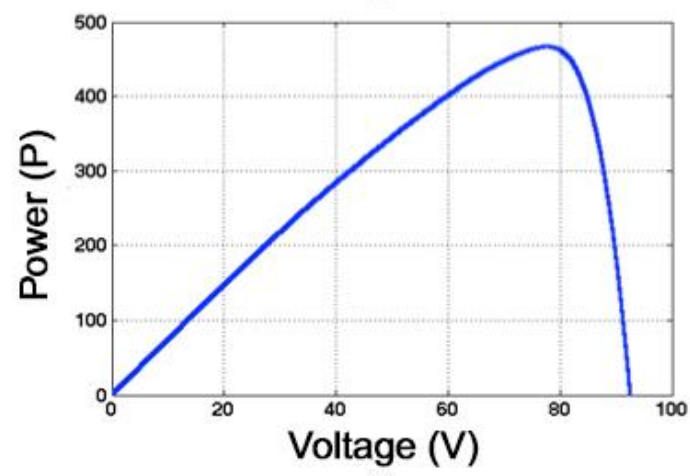

(f)

Fig.3.PV system (a), I-V characterictic of each row (b), P-V characterictic (c) before reconfiguration and after reconfiguration (d, e, f) with equalization DES 


\section{Reconfiguration algorithms}

\subsection{Dynamic programming $(D P)$}

DP algorithm (Riva Sanseverino et al., 2015) is used for Subset Sum problem in "Knapsack problems" (Martello and Toth, 1990). DP technique assesses for each panel the power able to be supplied and inserts it into a dynamic array, which will give rise to the connections between panels. With an intelligent method, DP shall select panels with total irradiation that are equal or close to the $a v g$ and then arrange them in a separated row.

\subsection{SmartChoice (SC)}

Dynamic Programming (DP) offers the best result in almost all cases, but in some special cases DP will not bring good results. Fig. 4 shows the DES in matrix form. Each entry of the matrix shows the irradiance level. Initial matrix gives average value avg $=2433 \mathrm{~W} / \mathrm{m}^{2}$, as explained in Riva Sanseverino et al., (2015) DP tries to fill the first row, by summing elements, in order to obtain a value that is equal or close to the average. In this way, first row has irradiance of $2300 \mathrm{~W} / \mathrm{m}^{2}$. According to Eq. (4), by considering DP selection, the EI index is:

$$
\mathrm{EI}_{\mathrm{DP}}=3000-2000=1000
$$

\begin{tabular}{|c|c|c|}
\hline 150 & 150 & 1000 \\
\hline 1000 & 1000 & 1000 \\
\hline 1000 & 1000 & 1000 \\
\hline Initial P matrix \\
\hline
\end{tabular}

Fig.4. Irradiance equalization using DP

\begin{tabular}{|l|l|l|l|l|}
\hline 1000 & 1000 & 150 & 150 & $\mathbf{= 2 3 0 0}$ \\
\hline 1000 & 1000 & & & $\mathbf{2 0 0 0}$ \\
\hline 1000 & 1000 & 1000 & & $\mathbf{= 3 0 0 0}$ \\
\hline \multicolumn{5}{|c|}{ After using DP } \\
\hline \multicolumn{3}{|c|}{} \\
\hline
\end{tabular}

A better result can be obtained by considering Fig. 5, in which initial matrix is the same but a better reconfiguration has been used. In such a way, EI becomes:

$$
\mathrm{EI}_{\text {BestResult }}=3000-2150=850
$$

\begin{tabular}{|c|c|c|}
\hline 150 & 150 & 1000 \\
\hline 1000 & 1000 & 1000 \\
\hline 1000 & 1000 & 1000 \\
\hline \multicolumn{3}{|c|}{ Initial P matrix } \\
\hline
\end{tabular}$\quad$\begin{tabular}{|c|c|c|c|}
\hline 1000 & 1000 & 150 & $\mathbf{= 2 1 5 0}$ \\
\hline 1000 & 1000 & 150 & $\mathbf{2 1 5 0}$ \\
\hline 1000 & 1000 & 1000 & $\mathbf{3 0 0 0}$ \\
\hline \multicolumn{5}{|c|}{ The best result } \\
\hline
\end{tabular}

Fig.5. An improved result due a smart reconfiguration.

To overcome the above-mentioned issue, the authors propose a second algorithm, the Smart Choice algorithm (SC), whose results can be compared on line with those of the DP algorithm, to choose the most performing strategy. The $\mathrm{SC}$ algorithm is described as follows.

In the first step, SC shall convert the starting matrix $\mathrm{G}$ into the data array A with $N$ (Eq.3) elements. By QuickSort arrangement method, array A shall be sorted from high to low level of the irradiation value. Initialize the matrix B with $m$ rows, then arrange some parts in the array A into rows of matrix B so that temporary EI index (applied for the matrix B) is the minimum value in each step.

Example to explain $S C$ algorithm

Initial matrix $\mathrm{G}$ is shown in Fig.6:

\begin{tabular}{|l|l|l|l|l|}
\hline 620 & 500 & 600 & 300 & $=\mathbf{2 0 2 0}$ \\
\hline 540 & 420 & 320 & 480 & $=\mathbf{1 7 6 0}$ \\
\hline 280 & 460 & 400 & 560 & $=\mathbf{1 7 0 0}$ \\
\hline 360 & 340 & 300 & 240 & $=\mathbf{1 2 4 0}$ \\
\hline
\end{tabular}

Fig. 6. Matrix G, case of study. 
By converting matrix G into an array A, Fig. 7 is obtained.

\begin{tabular}{|c|c|c|c|c|c|c|c|c|c|c|c|c|c|c|c|}
\hline 620 & 500 & 600 & 300 & 540 & 420 & 320 & 480 & 280 & 460 & 400 & 560 & 360 & 340 & 300 & 240 \\
\hline $\mathrm{A}(0)$ & $\mathrm{A}(1)$ & $\mathrm{A}[27]$ & $\mathrm{A}(3)$ & $\mathrm{A}(4)$ & $\mathrm{A}(5)$ & $\mathrm{A}(6)$ & $\mathrm{A}(7)$ & $\mathrm{A}(8)$ & $\mathrm{A}(9)$ & $\mathrm{A}(10)$ & $\mathrm{A}(11)$ & $\mathrm{A}(12)$ & $\mathrm{A}(13)$ & $\mathrm{A}(14)$ & $\mathrm{A}(15)$ \\
\hline
\end{tabular}

Fig. 7. Array A obtained by matrix G.

By sorting array A with QuickSort (Hoare, 1961), Array B, shown in Fig. 8, is obtained.

\begin{tabular}{|c|c|c|c|c|c|c|c|c|c|c|c|c|c|c|c|}
\hline 620 & 600 & 560 & 540 & 500 & 480 & 460 & 420 & 400 & 360 & 340 & 320 & 300 & 300 & 280 & 240 \\
\hline $\mathrm{A}(0)$ & $\mathrm{A}(1)$ & $\mathrm{A}[27]$ & $\mathrm{A}(3)$ & $\mathrm{A}(4)$ & $\mathrm{A}(5)$ & $\mathrm{A}(6)$ & $\mathrm{A}(7)$ & $\mathrm{A}(8)$ & $\mathrm{A}(9)$ & $\mathrm{A}(10)$ & $\mathrm{A}(11)$ & $\mathrm{A}(12)$ & $\mathrm{A}(13)$ & $\mathrm{A}(14)$ & $\mathrm{A}(15)$ \\
\hline
\end{tabular}

Fig. 8. Sorted array B.

Matrix B is obtained by putting each element of the array B (from i=0 to 15) as explained in Fig. 9.

\begin{tabular}{|c|c|c|c|c|c|c|c|c|c|c|c|c|c|}
\hline \multicolumn{4}{|c|}{ Step a } & \multicolumn{5}{|c|}{ Step b } & \multicolumn{5}{|c|}{ Step c } \\
\hline 620 & & & $=620$ & 620 & & & & $=620$ & 620 & & & & $=620$ \\
\hline & & & $=0$ & 600 & & & & $=600$ & 600 & & & & $=600$ \\
\hline & & & $=0$ & 560 & & & & $=560$ & 560 & & & & $=560$ \\
\hline & & & $=0$ & 540 & & & & $=540$ & 540 & 500 & & & $=1040$ \\
\hline \multicolumn{4}{|c|}{ Step d } & \multicolumn{5}{|c|}{ Step e } & \multicolumn{5}{|c|}{ Step f } \\
\hline 620 & 420 & & $=1040$ & 620 & 420 & 400 & & $=1440$ & 620 & 420 & 400 & & $=1440$ \\
\hline 600 & 460 & & $=1060$ & 600 & 460 & & & $=1060$ & 600 & 460 & & & $=1060$ \\
\hline 560 & 480 & & $=1040$ & 560 & 480 & & & $=1040$ & 560 & 480 & 360 & & $=1400$ \\
\hline 540 & 500 & & $=1040$ & 540 & 500 & & & $=1040$ & 540 & 500 & & & $=1040$ \\
\hline \multicolumn{4}{|c|}{ Step g } & \multicolumn{5}{|c|}{ Step h } & \multicolumn{5}{|c|}{ Step i } \\
\hline 620 & 420 & 400 & $=1440$ & 620 & 420 & 400 & & $=1440$ & 620 & 420 & 400 & 240 & $=1680$ \\
\hline 600 & 460 & 320 & $=1380$ & 600 & 460 & 320 & & $=1380$ & 600 & 460 & 320 & 300 & $=1680$ \\
\hline 560 & 480 & 360 & $=1400$ & 560 & 480 & 360 & & $=1400$ & 560 & 480 & 360 & 280 & $=1680$ \\
\hline 540 & 500 & 340 & $=1380$ & 540 & 500 & 340 & 300 & $=1680$ & 540 & 500 & 340 & 300 & $=1680$ \\
\hline
\end{tabular}

Fig. 9. Matrix B. Step a: element $i=0$ of array B is put as first element. Step b:first column is completed wit $i=1: 3$. Step c: element 4 is put in the minimum row value. Step d: column 2 takes remaining elements, the bigger value of array B on the minimum row value. Step e: the bigger element of array B is set on the minimum sum of the row values. Step f: the bigger element of array B is set on the minimum sum of the row values. Step g.: $3^{\text {th }}$ column is completed. Step h: first element of $4^{\text {th }}$ in the minimum value of sum of the rows. Step i : $4^{\text {th }}$ is completed.

Flow chart of SC is shown in Fig. 10. 


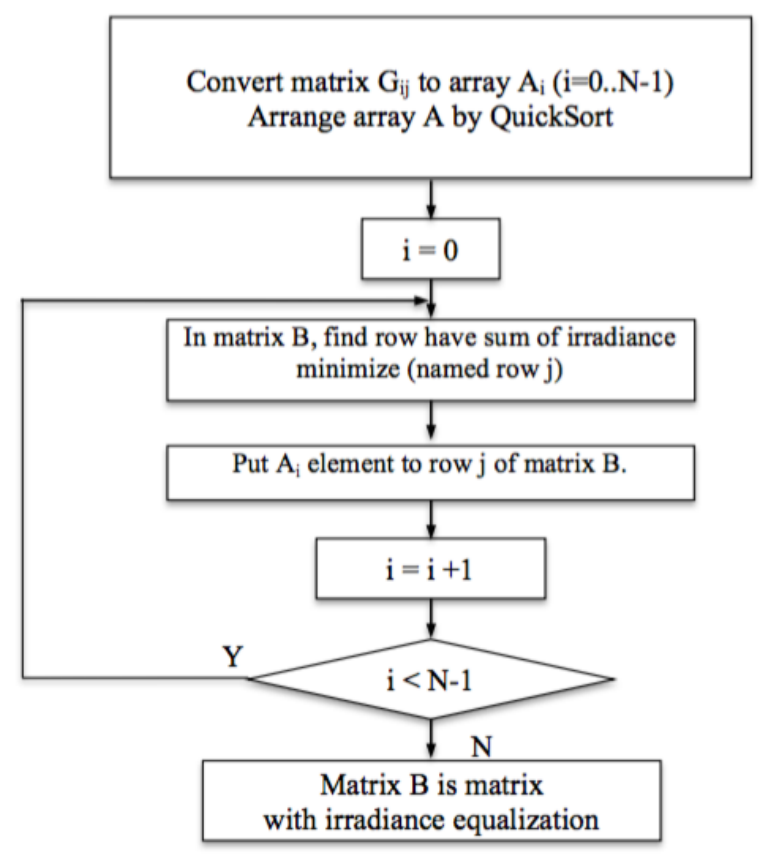

Fig. 10. Flowchart of SC algorithm

To find out the optimal result of the irradiation equalization problem, the authors propose to use a Hybrid method using both SC and DP running in parallel, which give improved results.

\section{Algorithm for optimal lifetime of DES}

After obtaining the result of the irradiation equalization problem, the MAA algorithm (Munkres, 1957) is used in order to minimize the switching operations in DES switching matrix to convert the starting matrix into the optimal matrix. Optimization of switching operations in DES switching matrix shall increase the lifetime of the switching matrix and the PV systems as well. However, in fact, if in the DES switching matrix, there is only one switch damaged, then all systems shall be repaired and replaced. So, if we just focus on minimization of switching operations in each reconfiguration without paying attention to switching operations of the whole switching matrix, it will cause nonhomogeneous usage among switches. The lifetime of the system shall depend on the lifetime of most-operated switches.

In Riva Sanseverino et al., (2015), the authors proposed a method to balance the switching operations of DES choosing the best among several optimal configurations. Therefore, instead of selecting a configuration with the minimum number of switching operations, a suboptimal configuration with homogenous aging of all switches in the matrix was chosen. This proposed method is presented in Fig.11. Based on the features of DP, it could generate many solutions with similar EI indices, that are close to the minimum. Then, the MAA algorithm, based on the current situation of the DES switching matrix, can provide a result so that switches in the switching matrix are used in a balanced way. 


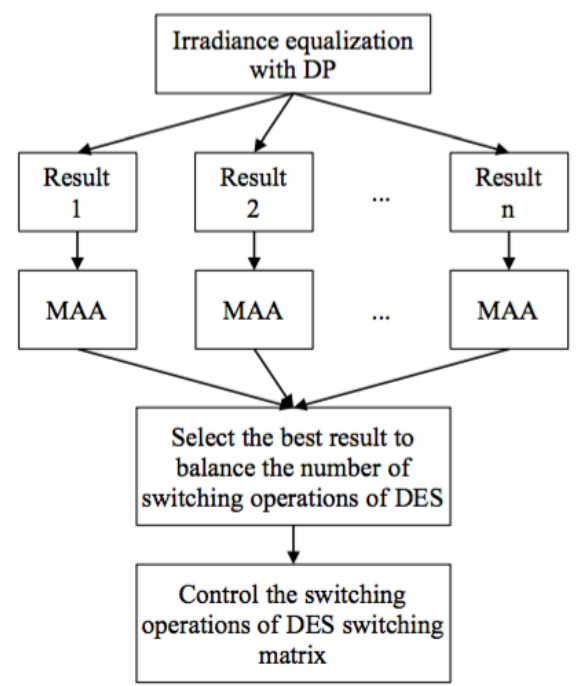

Fig.11. Balancing method for switching operation with MAA algorithm.

Figure 11 shows that different configurations are achieved, some with minor changes and others with major, from the starting configuration. By giving a priority to the balancing of the switches usage, it can happen that, between two suboptimal configurations, the one involving a slightly higher number of switching operations may be chosen.

It can be realized that, as proposed by the method in fig.11, running the MAA many times will increase the overall processing time. Therefore, the authors propose an improved strategy as described in Fig. 12.

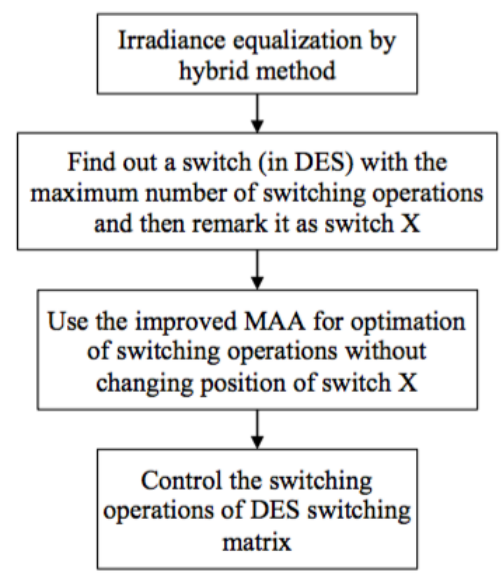

Fig. 12. Balancing method for switching operation with improved MAA algorithm

By using the improved strategy still using MAA, the switch with maximum number of switching operations shall be fixed and the method shall control the switching operations of other switches so that results of irradiance equalization do not change, still ensuring the switching operation balancing of switches in the DES matrix in order to increase the lifetime of the system. When the solar power systems is in operation, PV panels could be shaded by the shadow of trees, buildings, electric lines and columns. This further leads to the problem that some panels shall be shaded several times in a day and switches of such panels shall operate more than switches of other panels. The improved MAA solves this situation. In addition, in the improved MAA method, MAA algorithm is run once helping to reduce the processing speed as compared to the old method. 


\section{Method to increase efficiency of the solar power systems}

Based on the above-described algorithms, the overall methodology for increasing the efficiency of the PV system by reconfiguration is summarized in the flow chart shown in Fig. 13. As it can be observed, after the irradiance estimation both DP and SC are run in parallel and the best performing solution is taken. Then the improved MAA is adopted to minimize the ageing of the switching matrix.

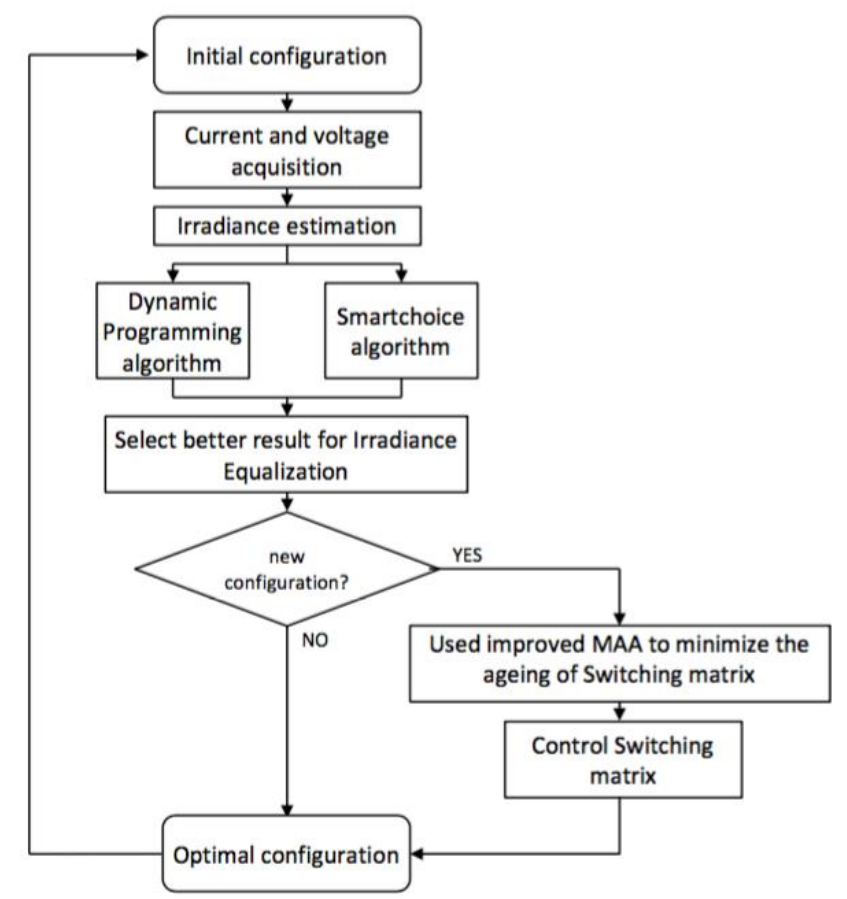

Fig. 13. Flow chart of reconfiguration method for solar power systems.

\section{Experiments}

\subsection{Simulation}

In order to prove the efficiency of the improved method, the simulation of a solar power system including 35 PV panels connected in TCT topology is illustrated in Fig. 14a. The PV system is partially shaded by a line passing through. Depending on position of the sun in a day, the panels $(12,13,14, \ldots, 35)$ shall be shaded partially with various degree.

The authors establish a solar radiation database in 12 times in a day with various shading degree of the panels (fig.14). DES switching matrix (Fig. 1b) is installed to rearrange to connect 35 panels with 5 rows each, so 175 switches shall be used. 


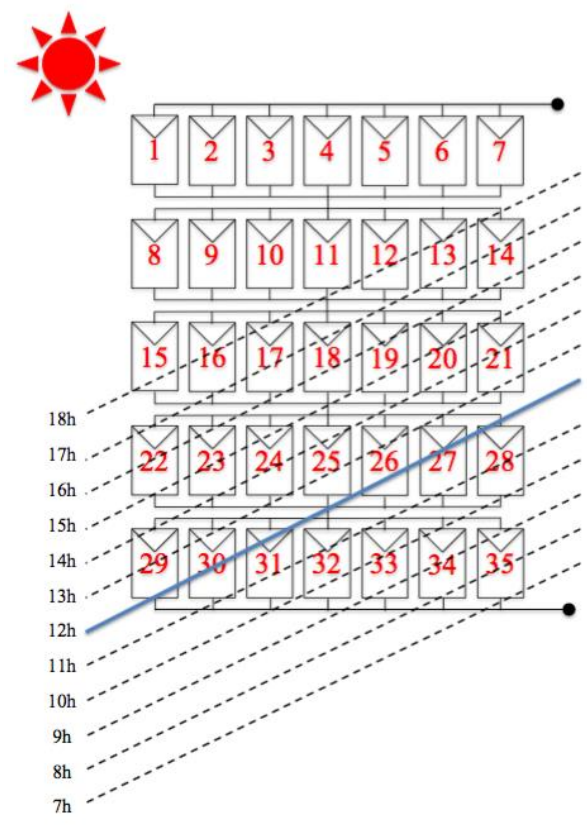

(a)

\begin{tabular}{|c|c|c|c|c|}
\hline \multirow{2}{*}{ No. } & \multirow{2}{*}{ Time } & \multicolumn{2}{|c|}{$\begin{array}{c}\text { Radiation degree } \\
\left(\mathbf{W} / \mathbf{m}^{2}\right)\end{array}$} & \multirow{2}{*}{ Partial shading solar } \\
& & $\begin{array}{c}\text { Non- } \\
\text { partial } \\
\text { shading }\end{array}$ & $\begin{array}{c}\text { Partial } \\
\text { shading }\end{array}$ & \\
\hline 1 & $7 \mathrm{~h}$ & 500 & 150 & $(35)$ \\
\hline 2 & $8 \mathrm{~h}$ & 650 & 300 & $(34,35)$ \\
\hline 3 & $9 \mathrm{~h}$ & 750 & 350 & $(33,34,35)$ \\
\hline 4 & $10 \mathrm{~h}$ & 850 & 350 & $(32,33,34,28)$ \\
\hline 5 & $11 \mathrm{~h}$ & 950 & 400 & $(30,31,32,33,27,28)$ \\
\hline 6 & $12 \mathrm{~h}$ & 1000 & 450 & $(29,30,31,26,27,28)$ \\
\hline 7 & $13 \mathrm{~h}$ & 950 & 400 & $(29,30,25,26,21)$ \\
\hline 8 & $14 \mathrm{~h}$ & 850 & 350 & $(29,23,24,25,20,21)$ \\
\hline 9 & $15 \mathrm{~h}$ & 750 & 350 & $(22,23,24,19,20,21)$ \\
\hline 10 & $16 \mathrm{~h}$ & 650 & 300 & $(22,23,18,19,14)$ \\
\hline 11 & $17 \mathrm{~h}$ & 500 & 150 & $(22,16,17,18,13,14)$ \\
\hline 12 & $18 \mathrm{~h}$ & 400 & 100 & $(15,16,17,12,13,14)$ \\
\hline
\end{tabular}

(b)

Fig. 14. Data of partial shading of the simulation solar system: PV array under partial shading (a) irradiance of PV panel under partial shading (b)

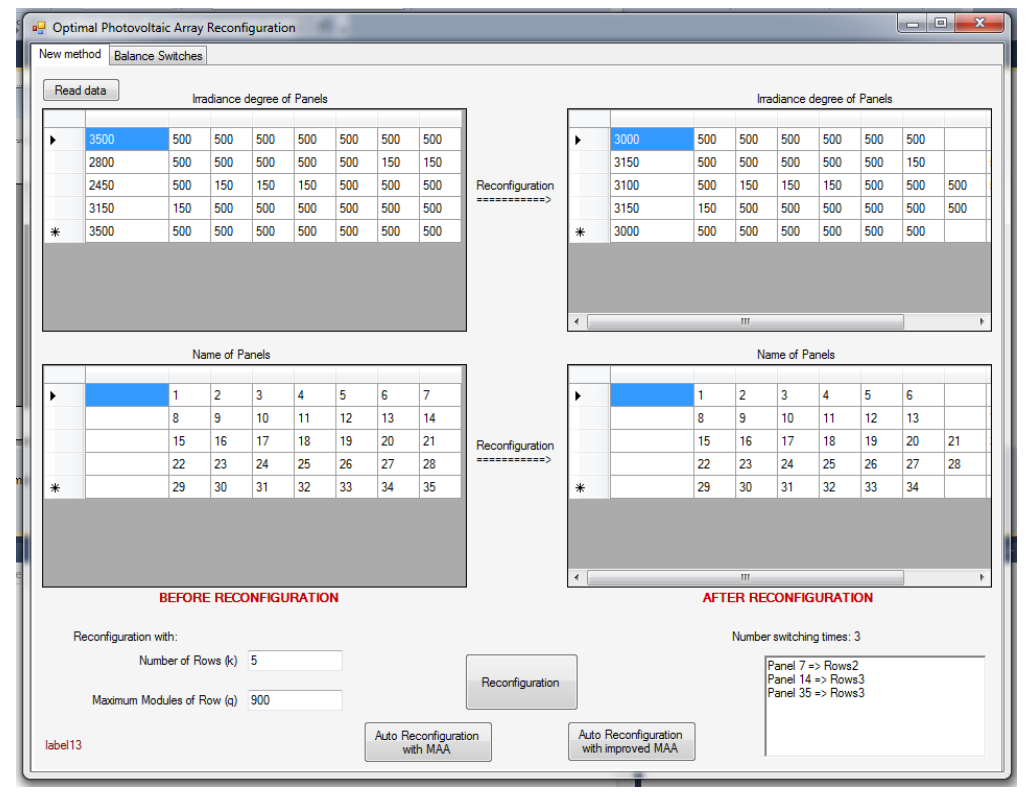

Fig.15. Optimal photovoltaic array reconfiguration software

Simulation software is written on C\# base by Microsoft Visual Studio 2010 a snapshot of which is reported in Fig.15. By simulating the operation of the solar system (Figure 14) with 12 cases of daily various shading, this procedure is repeated for 365 days/year. Diagram in Fig. 16 shows in details the number of switching operations for 175 switches of 35 solar panels in a year. Blue line is the simulation case by MAA method with the number of switching operations in which the maximum number of operation of a switch can reach 386. Fig. 16 shows the improved MAA method in which the number of operations of switches is more homogenous and the maximum number 
of switching operations is 246 . It can be realized that the total number of switching operations in the new method (12958 times) is more than in the old method (11405 times) but the aging degree of switches is more homogenous. Therefore, the lifetime of the whole switching matrix would increase by $56 \%$ in this simulation case. Indeed the maximum number of switching operations using MAA method is 386; using improved MAA is 246; then (386$246) / 246 * 100 \%=56 \%$. The aging of the reconfigurator is an important issue: recovered energy, with the particular feed-in tariff, has to repay the cost of the reconfigurator, an unexpected falling-out of the device may preclude the achievement of the trade-off ( Campoccia et al., 2014; Campoccia et al., 2008, Viola et al., 2014, Viola et al., 2015).

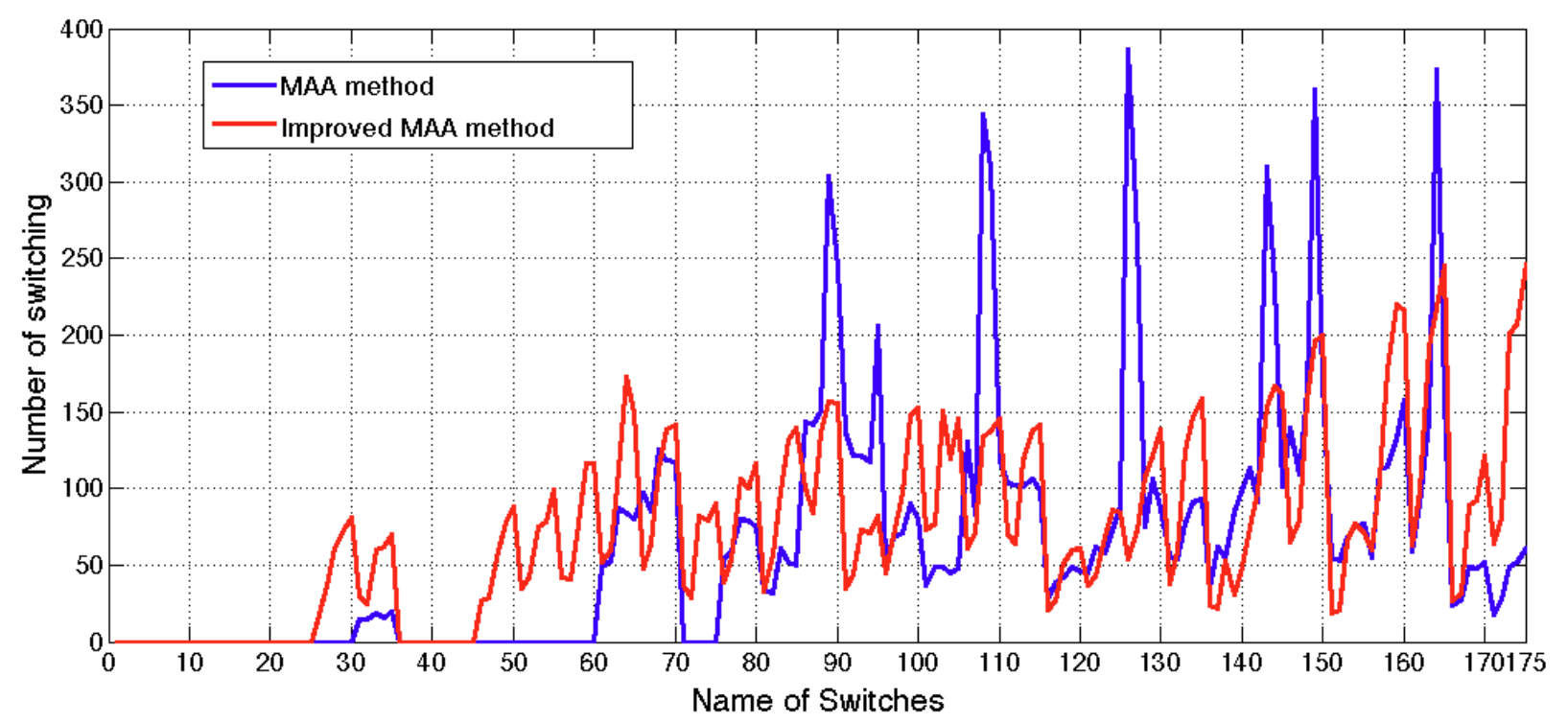

Fig. 16. Comparison of switching operations between (a) the old MAA method and (b) the improved MAA method

\subsection{Laboratory experiment}

The experimental part of this work has been carried out at the laboratory at the Electric Power University in Hanoi Vietnam.

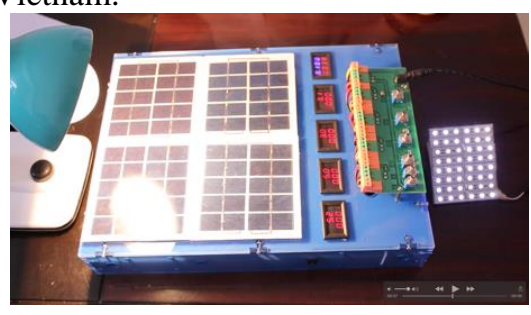

(a)

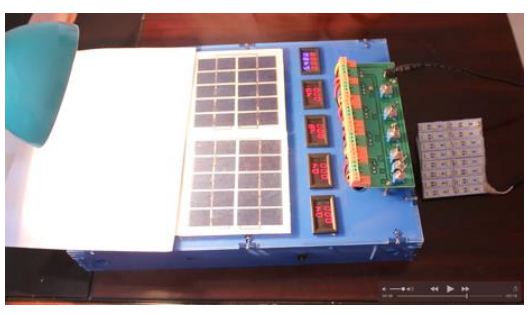

(b)

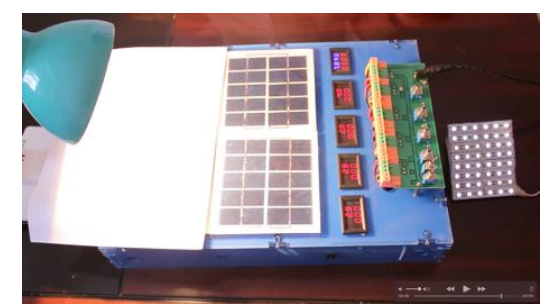

(c)

Fig. 17. PV system with reconfigurator: a) Normal; b) Patial Shading; c) After reconfiguration

To assess the efficiency of the proposed algorithm, the authors have implemented at laboratory scale a PV system (Fig. 17) including: a solar simulator, 4 solar panels (rated power shown in Table 1); 4 current and voltage acquisition systems for the 4 panels; 1 current and voltage acquisition for output power of PV system; DES switching matrix and a LED lighting is the load of PV system.

Table 1. Electrical Characteristics of PV used Modules at $25^{\circ} \mathrm{C}$

\begin{tabular}{|c|c|c|c|c|}
\hline $\mathrm{V}_{\mathrm{MPP}}$ & $\mathrm{I}_{\mathrm{MPP}}$ & $\mathrm{P}_{\mathrm{MPP}}$ & $\mathrm{V}_{\mathrm{OC}}$ & $\mathrm{I}_{\mathrm{SC}}$ \\
\hline $18 \mathrm{~V}$ & $0.33 \mathrm{~A}$ & $6 \mathrm{~W}$ & $21.6 \mathrm{~V}$ & $0.4 \mathrm{~A}$ \\
\hline
\end{tabular}




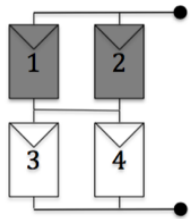

(a)

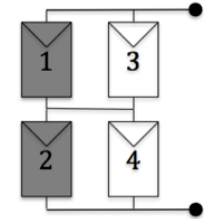

(b)

Fig. 18. Connection of PV system before (a) and after (b) reconfiguration

Figure 13 describes the operation process of a reconfiguration system for PV system in DC current. Fig. 17a shows the PV system that is operating in normal mode where LED lights are very bright, non-partial shading. Fig. 17b shows the system in the case in which the panel 1 and panel 2 are shaded (as you can see in Fig. 18a), LED lights are falling due to the inefficiency of the source. Besides, Fig. 17c shows the PV system after reconfiguration (as connection in Fig.18b), that helps to recover a part of power generated due to partial shading. At this moment, LED lights are bright again but they are not as bright as initially.

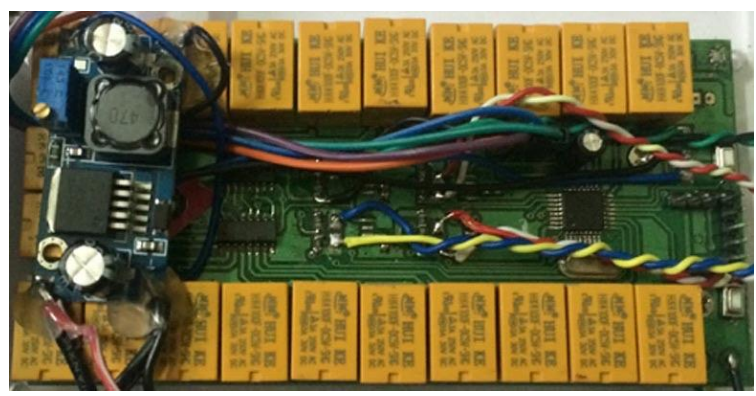

Fig. 19. Reconfiguration system

In self-operating mode, the reconfiguration system (including DES switching matrix and Controller chips), shown in details in Fig. 19, that is programmed for operation in each minute shall measure the current and voltage on each solar panel, then, the irradiation degree on each panel is calculated. Compared with the previously calculated result, if irradiation variance exceeds allowable limitation, the reconfiguration system shall automatically calculate and control the switching matrix to obtain the optimal configuration for output power. And, in case the system is shaded for a short time (below 1 minute) or less shaded (not exceed the limitation), the reconfiguration system shall not operate. The efficiency of the reconfiguration system is then checked by shading each part of solar panels with various shading degree chronologically. Output power is then measured and compared in case of reconfiguration system activation and no reconfiguration system activation.

Solar power system with automatic reconfiguration system operated well as shown by the results reported in Table 2 and Fig. 20.

Table 2. Operation of reconfiguration system for optimal PV system in 13 case of patial shading

\begin{tabular}{|c|c|c|c|c|c|c|c|c|c|c|}
\hline \multirow{2}{*}{ Case } & \multicolumn{4}{|c|}{ degree of partial shading $(\%)$} & \multicolumn{2}{|c|}{ Connection } & \multirow{2}{*}{$\begin{array}{l}\text { Number of } \\
\text { switching }\end{array}$} & \multicolumn{2}{|c|}{ Ouput power $(\mathrm{W})$} & \multirow{2}{*}{$\begin{array}{l}\text { Increasing } \\
\text { efficiency } \\
\quad(\%)\end{array}$} \\
\hline & Panel 1 & Panel 2 & Panel 3 & Panel 4 & Intial & $\begin{array}{c}\text { after } \\
\text { reconfiguration }\end{array}$ & & Intial & $\begin{array}{c}\text { after } \\
\text { reconfiguration }\end{array}$ & \\
\hline 1 & 0 & 0 & 0 & 0 & $\{1 \| 2\}--\{3|| 4\}$ & $\{1 \| 2\}--\{3 \| 4\}$ & 0 & 23.75 & 23.75 & 0.00 \\
\hline 2 & 10 & 0 & 0 & 0 & $\{1 \| 2\}--\{3 \| 4\}$ & $\{1 \| 2\}--\{3 \| 4\}$ & 0 & 23.04 & 23.04 & 0.00 \\
\hline 3 & 10 & 10 & 0 & 0 & $\{1 \| 2\}--\{3 \| 4\}$ & $\{1 \| 3\}--\{2 \| 4\}$ & 2 & 22.13 & 22.6 & 2.12 \\
\hline 4 & 20 & 20 & 0 & 0 & $\{1 \| 2\}--\{3 \| 4\}$ & $\{1 \| 3\}--\{2 \| 4\}$ & 2 & 20.03 & 21.38 & 6.74 \\
\hline 5 & 30 & 30 & 0 & 0 & $\{1 \| 2\}--\{3 \| 4\}$ & $\{1 \| 3\}--\{2 \| 4\}$ & 2 & 17.73 & 20.18 & 13.82 \\
\hline 6 & 40 & 40 & 0 & 0 & $\{1 \| 2\}--\{3 \| 4\}$ & $\{1 \| 3\}--\{2 \| 4\}$ & 2 & 15.34 & 18.98 & 23.73 \\
\hline
\end{tabular}




\begin{tabular}{|c|c|c|c|c|c|c|c|c|c|c|}
\hline 7 & 50 & 50 & 10 & 10 & $\{1 \| 2\}--\{3 \mid 4\}$ & $\{1|| 3\}--\{2 \| 4\}$ & 2 & 12.8 & 16.6 & 29.69 \\
\hline 8 & 60 & 60 & 60 & 0 & $\{1 \| 2\}--\{3 \| 4\}$ & $\{1\|2\| 3\}--\{4\}$ & 1 & 10.18 & 12.33 & 21.12 \\
\hline 9 & 70 & 70 & 70 & 0 & $\{1 \| 2\}--\{3 \| 4\}$ & $\{1\|2\| 3\}--\{4\}$ & 1 & 7.66 & 11 & 43.60 \\
\hline 10 & 75 & 75 & 0 & 50 & $\{1 \| 2\}-\{3 \| 4\}$ & $\{1\|2\| 4\}--\{3\}$ & 1 & 8.54 & 11.79 & 38.06 \\
\hline 11 & 80 & 80 & 80 & 40 & $\{1 \| 2\}-\{3 \| 4\}$ & $\{1\|2\| 3\}--\{4\}$ & 1 & 5.04 & 7.02 & 39.29 \\
\hline 12 & 75 & 75 & 50 & 50 & $\{1 \| 2\}-\{3 \| 4\}$ & $\{1|| 3\}--\{2 \| 4\}$ & 2 & 6.34 & 8.8 & 38.80 \\
\hline 13 & 75 & 75 & 75 & 75 & $\{1 \| 2\}--\{3 \| 4\}$ & $\{1 \| 2\}--\{3 \| 4\}$ & 0 & 5.81 & 5.81 & 0.00 \\
\hline
\end{tabular}

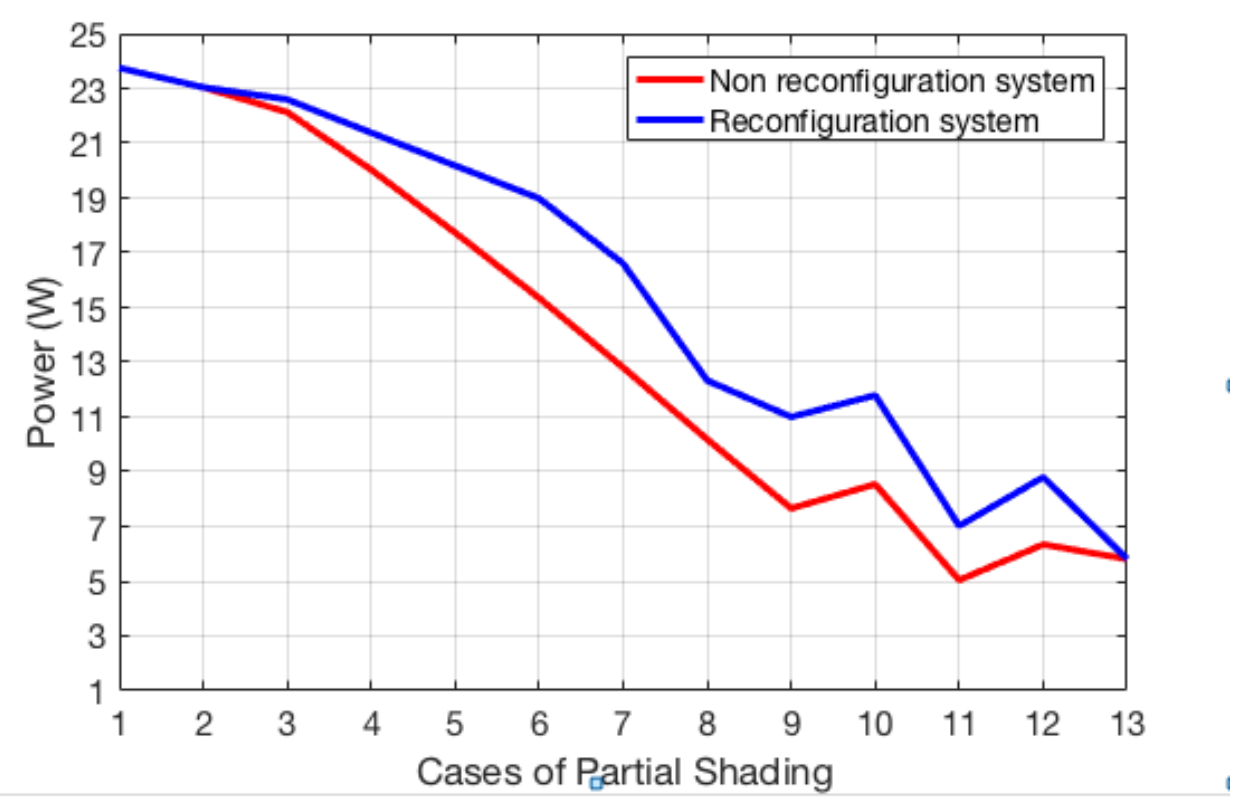

Fig. 20. Diagram comparing the output power of the solar power system with the reconfiguration system and without reconfiguration system when in PS situations

\section{Conclusion}

The method proposed in this paper should be applied to small PV systems, although one of the objectives of this work is to propose similar strategies for larger photovoltaic fields. In those cases, improvement in output power could bring large benefits in terms of feed-in tariffs when available or simply produced clean energy. Another possible evolution of this work is the use of solid state switches. In this case the problem of obsolescence would not be anymore a big issue. However, these switches do not still seem to be easily controllable while showing some problems for high power applications and thus electromechanical relays still seem to be the best option at this stage. This paper presents improved methods in order to increase the efficiency of the solar power system and lengthen the lifetime of the system by balancing the switching operations of the switching matrix based on electromechaincal relays. By running in parallel the newly proposed Smart Choice algorithm and a Dynamic Programming algorithm an optimal result for the irradiance equalization problem is attained. Then an improvement of the MAA algorithm helps to further save operation time of the system and offer an optimal switching operation control result while increasing the lifetime of the system. The operation of a reconfiguration system on a solar power system with 35 panels with various shading degrees in a day is simulated, then, experimental results on a smaller system demonstrated the efficiency of the new method. This improved method could be applied in real time to increase the quality of current solar systems. Future work about the same issue will imply the extension of the methodology to larger systems and a detailed economical 
analysis based on the results of (Viola et al., 2016., Caruso et al., 2017) to assess the return on investment time of the whole system.

\section{References}

Adnan Z. Amin, Renewable power generation costs in 2014, Adnan Z. Amin, Editor. 2015: International Renewable Energy Agency.

Alahmada M., Amer Chaabanb M., Kit Laua S., Shic J., Neald J., An adaptive utility interactive photovoltaic system based on a flexible switch matrix to optimize performance in real-time. Solar Energy, 2012. 86: p. 951-963.

Balato M., Costanzo L., Vitelli M., Maximum Power Point Tracking Techniques. Wiley Encyclopedia of Electrical and Electronics Engineering, 2016: p. 1-26.

Belhachata F., Larbesb C., Modeling, analysis and comparison of solar photovoltaic array configurations under partial shading conditions. Solar Energy, 2015. 120: p. 399-418.

Campoccia A., Dusonchet L., Telaretti E., Zizzo G., An analysis of feed'in tariffs for solar PV in six representative countries of the European Union. Solar Energy, 2014. 107: p. 530-542.

Campoccia A., Dusonchet L., Telaretti E., Zizzo G., Comparative analysis of different supporting measures for the production of electrical energy by solar PV and Wind systems: Four representative European cases. Solar Energy, 2008. 83(3): p. 287-297.

Caruso, M., Di Noia, L.P., Romano, P., Schettino, G., Spataro, C., Viola, F., PV reconfiguration systems: A technical and economic study, (2017) Journal of Electrical Systems, 13 (1), pp. 55-73.

Delinea Chris, Dobosa Aron, Janzoua Steven, Meydbray Jenya, Donovanb Matt, A simplified model of uniform shading in large photovoltaic arrays. Solar Energy, 2013. 96: p. Pages 274-282.

Femia N., Petrone G., Spagnuolo G., Vitelli M., Power Electronics and Control Techniques for Maximum Energy Harvesting in Photovoltaic systems. 2012.

Hideaki Obane ,Keiichi Okajima,Takashi Oozeki, Takafumi Ishii, PV System With Reconnection to Improve Output Under Nonuniform Illumination. IEEE Journal of Photovoltaics, 2012. 2(3): p. 341 - 347.

Hoare C. A. R., Algorithm 64: Quicksort. Communications of the ACM, July 1961 4(7): p. 321.

International Energy Agency, Trends in photovoltaic applications. Survey report of selected IEA countries between 1992 and 2012. 2013 International Energy Agency.

Jian Zhaoa, Xuesong Zhoub, Youjie Mab, Wei Liub, A novel maximum power point tracking strategy based on optimal voltage control for photovoltaic systems under variable environmental conditions. Solar Energy, 2015. 122: p. 640-649.

Kouchaki Alireza, Hossein Iman-Eini, Behzad Asaei, A new maximum power point tracking strategy for PV arrays under uniform and non-uniform insolation conditions. Solar Energy, 2013. 91: p. 221-232.

La Manna D., Li Vigni V, Riva Sanseverino E, Di Dio V, Romano P., Reconfigurable electrical interconnection strategies for photovoltaic arrays: A review. Renewable and Sustainable Energy Reviews, 2014.

Lynn, P., Electricity from sunlight: an introduction to photovoltaics. Choice: Current Reviews for Academic Libraries, 2011. 48(5): p. 933-933.

Martello S., Toth P., Subset-sum problem. Ebook - Knapsack Problems - Algorithms and Computer Implementations. 1990. 105-130.

Munkres J., Algorithms for Assignment and Transportation Problems. Journal of the Society for Industrial and Applied Mathematics, 1957. 5.

Negroni J.J., Vera, Gispert F. G., Piqué R., Irradiance equalization method for output power optimization in plant oriented grid-connected PV generators. Power Electronics and Applications, 2005 European Conference on, 2005: p. 10 pp. - P.10.

Nguyen Dzung, Lehman B., An adaptive solar photovoltaic array using model-based reconfiguration algorithm. Ieee Transactions on Industrial Electronics, 2008. 55(7): p. 2644-2654.

Picault D., Raison B., Bacha S., Aguilera J., De La Casa J., Changing photovoltaic array interconnections to reduce mismatch losses: a case study. Environment and Electrical Engineering (EEEIC), 2010 9th International Conference on, 2010: p. 37 - 40.

Po-Cheng Chena, Po-Yen Chena, Yi-Hua Liua, Jing-Hsiao Chena, Yi-Feng Luob, A comparative study on maximum power point tracking techniques for photovoltaic generation systems operating under fast changing environments. Solar Energy, 2015. 119: p. 261-276. 
Riva Sanseverino E., Ngo Ngoc T., Cardinale M., Li Vigni V., Musso D., Romano P., Viola F., Dynamic programming and Munkres algorithm for Optimal Photovoltaic Arrays Reconfiguration. Solar Energy, 12/2015. 122: p. Pages 347-358.

Romano P., Candela R.., Cardinale M., Li Vigni V., Musso D., Riva Sanseverino E., Optimization of photovoltaic energy production through an efficient switching matrix. Journal of Sustainable Development of Energy, Water and Environment Systems, 2013. 1(3): p. 227-236.

Shams El-Dein M. Z., Mehrdad Kazerani, Salama M. M. A., Optimal Photovoltaic Array Reconfiguration to Reduce Partial Shading Losses. IEEE TRANSACTIONS ON SUSTAINABLE ENERGY, 2012. 4(1): p. 9.

Storey, J.P. ; Sch. of Electron. \& Comput. Sci., Univ. of Southampton, Southampton, UK ; Wilson, P.R. ; Bagnall, D., Improved Optimization Strategy for Irradiance Equalization in Dynamic Photovoltaic Arrays. Power Electronics, IEEE Transactions on, 2012. 28(6): p. 11.

Veerachary M. ; Senjyu T., Uezato K., Voltage-based maximum power point tracking control of PV system. IEEE Transactions on Aerospace and Electronic Systems, Jan 2002. 38(1): p. 262 - 270.

Velasco G, Guinjoan F., Piqué R., Electrical PV Array Reconfiguration Strategy for Energy Extraction Improvement in Grid-Connected PV Systems. Ieee Transactions on Industrial Electronics, 2009. 56(11): p. 4319-4331.

Viola F., Romano P.; Miceli R.,; Spataro C.; Schettino G., Technical and economical evaluation on the use of a reconfiguration systems in some EU countries for PV plants, IEEE Transactions on Industry Applications, Year: 2016, Volume: PP, Issue: 99, DOI: 10.1109/TIA.2016.2625771

Viola, F. , Romano, P. , Miceli, R, Spataro, C., Schettino, G., Fanto, F , Economic benefits of the use of a PV plants reconfiguration systems, 2015 International Conference on Renewable Energy Research and Applications, ICRERA 2015, Palermo, Italy, 22-25 November 2015

Viola, F. , Romano, P., Sanseverino, E.R., Miceli, R., Cardinale, M., Schettino, G, An economic study about the installation of PV plants reconfiguration systems in Italy 3rd International Conference on Renewable Energy Research and Applications, ICRERA 2014, Milwaukee; United States; 19-22 October 2014

Woytea Achim, J.N., Ronnie Belmans, Partial shadowing of photovoltaic arrays with different system configurations: literature review and field test results. Solar Energy, 2003. 74: p. 17.

Yi-Hua Liua, Jing-Hsiao Chena, Jia-Wei Huangb, Global maximum power point tracking algorithm for PV systems operating under partially shaded conditions using the segmentation search method. Solar Energy, 2014. 103: p. 350-363.

Zhang F., Maddy J., Premier G., Guwy A., Novel current sensing photovoltaic maximum power point tracking based on sliding mode control strategy. Solar Energy, 2015. 118: p. 80-86. 